\title{
PODER NA ADMINISTRAÇÃO, ADMINISTRAÇÃO PÚBLICA, CONTABILIDADE E TURISMMO
}

POWER IN ADMINISTRATION, PUBLIC ADMINISTRATION, ACCOUNTING AND TOURISM

\section{Raimunda Letícia do Nascimento}

Universidade Federal do Ceará (UFC), Fortaleza/CE, BRASIL

admleticianascimento@gmail.com

\section{Teresa Cristina Aguiar Lima}

Universidade de Coimbra, Coimbra, PORTUGAL

teresa.lima.ufc@gmail.com

\section{Augusto Cézar de Aquino Cabral}

Universidade Federal do Ceará (UFC), Fortaleza/CE, BRASIL

cabral@ufc.br

\section{Sandra Maria dos Santos}

Universidade Federal do Ceará (UFC), Fortaleza/CE, BRASIL smsantos@ufc.br

\section{Resumo}

Esse artigo tem como objetivo geral analisar a produção científica brasileira sobre poder na área de Administração, Administração Pública, Contabilidade e Turismo. Trata-se de um estudo exploratório-descritivo com abordagem quantitativa, utilizando o método de pesquisa bibliométrico. Os artigos analisados foram localizados na base de dados Scientific Periodicals Electronic Library (SPELL). Observou-se movimentos de ascensão e declínio das publicações no período estudado (2006 a 2016). Os temas mais abordados foram relações, redes e conhecimento. As pesquisas são empíricas, de abordagem qualitativa, de natureza descritiva, predominando o procedimento estudo de caso, o método de coleta entrevista e a análise de conteúdo. Constatou-se, também, que o setor mais estudado são as instituições de ensino superior e o perfil de autoria é de dois autores por artigo, sendo doutores da região sudeste.

Palavras-chave: Poder. Estudo bibliométrico. Produção científica.

\section{Abstract}

This article aims to analyze the Brazilian scientific production about power in the area of administration, public administration, accounting and tourism. This is an exploratory-descriptive study with a quantitative approach, using the bibliometric research method. The analyzed articles was found in the Scientific Periodicals Electronic Library (SPELL) database. Movements of ascension and decline of publications during the studied period (2006 to 2016) were observed. The most discussed themes were relationships, networks and knowledge. The researches are empirical, with a qualitative approach, of a descriptive nature, predominating the case study procedure, the interview collection method and the content analysis. It was also verified that the sector most studied are institutions of higher education and the authorship profile is two authors per article, being doctors from the southeast region.

Keywords: Power. Bibliometric study. Scientific production. 


\section{Introdução}

A história de investigação do poder iniciou no século XVI, com um enfoque centrado no poder do Estado (PAZ; MARTINS; NEIVA, 2004). No campo das organizações, os estudos do poder iniciaram com Marx e Weber (HARDY; CLEGG, 2001). É um tema relevante e que foi objeto de investigação de vários pesquisadores. Os fenômenos do poder manifestamse de formas diferentes e são objetos de diversos modos de observação e análise (FISCHER, 2001).

Estudos bibliométricos anteriores estudaram as publicações sobre as relações de poder em redes de negócios (OLIVEIRA; SACOMANO NETO; BOAVENTURA, 2016) e a produção científica que relacionava os constructos poder e política (SANTOS; CLARO, 2014). Entretanto, o poder se relaciona com temas diversos como: legitimidade, disciplina, gênero, identidade, estrutura formal e informal, dentre outros (HARDY; CLEGG, 2001). Assim, faz-se necessário analisar as publicações desse fenômeno de forma mais abrangente, envolvendo os seus diversos eixos temáticos. Isso posto, definiu-se a questão de pesquisa: como se caracteriza a produção científica brasileira sobre poder na área de administração, administração pública, contabilidade e turismo?

O presente trabalho se propõe a fazer a análise quantitativa das publicações dos periódicos indexados na base de dados SPELL (Scientific Periodicals Eletronic Library), no período de 2006 a 2016, apresentando como contribuição fornecer um panorama da produção científica catalogada nessa base.

Foram definidas as seguintes hipóteses: (1) a produção científica sobre o fenômeno poder cresceu nos últimos anos; (2) a temática mais recorrente é a política; (3) os procedimentos metodológicos predominantes são: abordagem qualitativa, com ênfase em estudo de caso, de natureza exploratória, utilizando como técnica de coleta a entrevista e para a análise dos dados a análise de conteúdo; (4) o setor mais estudado são as instituições de ensino superior e (6) as pesquisas foram realizadas predominantemente por três autores, doutores e vinculados à universidades da região sudeste.

Assim, o estudo tem como objetivo geral analisar a produção científica brasileira sobre poder na área de administração, administração pública, contabilidade e turismo. Apresenta como objetivos específicos: (a) verificar a evolução da produção científica sob esse enfoque; (b) identificar os principais eixos temáticos; (c) identificar os procedimentos metodológicos adotados; (d) identificar os campos ou setores mais estudados e (e) identificar o perfil de autoria.

Para atingir o objetivo desta pesquisa, realizou-se um estudo exploratório-descritivo com abordagem quantitativa, utilizando o método de pesquisa bibliométrico. Os procedimentos técnicos são documentais, mediante consulta aos periódicos indexados na base de dados SPELL no período de 2006 a 2016.

O artigo está organizado em cinco seções. A primeira seção corresponde a esta introdução, a segunda seção aborda a fundamentação teórica, a terceira seção refere-se à metodologia do trabalho, a quarta seção consiste no levantamento e análise dos dados e, por fim, na quinta seção apresentam-se as conclusões.

\section{Referencial teórico}

Para analisar a produção científica sobre poder na área de administração, administração pública, contabilidade e turismo expõe-se, a seguir, um referencial teórico contendo os seguintes tópicos: (1) o estudo sobre poder e (2) pesquisas anteriores da produção científica sobre poder.

\section{O estudo sobre poder}

Existem muitas definições para poder. Hardy e Clegg (2001), baseando-se nos estudos de Weber, conceituam como a habilidade de fazer com que os outros façam o que você quer que seja feito, se necessário contra a própria vontade deles. Para Faria (2001), o poder é a capacidade de definir e realizar seus interesses objetivos específicos, mesmo contra a resistência a seu exercício e independente do nível estrutural em que ela esteja fundamentada.

Kich et al. (2012, p. 89) destacam a "multiplicidade de vozes diferentes que falam sobre o poder. Os seus conceitos estão inscritos nas diversas áreas do conhecimento, sob distintos enfoques, independentemente da área a que pertençam”. Fischer (2001) considera que as definições de poder são vozes destoantes e os estudos sobre esse fenômeno devem abrir espaço para tal distonia, visto que ele se manifesta de formas diferentes e é objeto de diversos modos de observação e análise. Hardy e Clegg (2001) agrupam essas vozes em dois ramos divergentes de pesquisa: um funcionalista e outro crítico. 
A perspectiva funcionalista deriva do trabalho de Marx e Weber. Ela considera a existência de conflitos de interesses e trata o poder como uma forma de dominação. Nesse sentido, mostra como o poder penetra nas estruturas organizacionais de modo a servir a alguns, mas não a todos os grupos de interesse. O poder era visto como dominação e as ações que visavam confrontar isso constituíam-se em resistência à dominação. Ele era legitimado na forma de estruturas organizacionais (HARDY; CLEGG, 2001).

A perspectiva crítica se desenvolveu a partir do próprio campo dos estudos organizacionais. Ela aceita por verdadeiro o modo pelo qual o poder é distribuído na estrutura das organizações formais e, então, examina como diversos grupos adquirem e mantêm um poder não concedido a eles oficialmente. A visão que se tem do poder é de resistência, mas de uma espécie ilegítima, disfuncional. Define-se o poder como aquelas ações que estão fora das estruturas legitimadas e que ameaçavam os objetivos organizacionais (HARDY; CLEGG, 2001).

A permeabilidade do fenômeno torna praticamente impossível captá-lo inteiramente, uma vez que há poder em todos os lugares, e, além disso, ele pode ser explorado sob diversos ângulos (KICH et al,. 2012). Segundo Bourdieu (1998), o poder não é totalmente visível o tempo todo para todas as pessoas, dessa forma nem sempre os seus mecanismos são visíveis. Entretanto, esse tema é instigante e tem sido amplamente discutido nos estudos organizacionais, assim como em vários outros ramos das ciências sociais (CAPPELLE; MELO; BRITO, 2005). Expõe-se a seguir uma síntese sobre os artigos que estudaram a produção científica sobre o poder.

\section{Pesquisas anteriores da produção científica sobre poder}

A produção científica sobre o fenômeno poder foi analisada por: Giglio, Pugliese e Silva (2012), Santos e Claro (2014) e Oliveira, Sacomano Neto e Boaventura (2016). Esses trabalhos sugerem a associação de poder a outros temas.

O Quadro 1 apresenta o objetivo geral, a metodologia e os resultados desses trabalhos bibliométricos. Esses trabalhos contribuíram para um diagnóstico da produção científica sobre poder, porém restringiram-se a apenas um tema. O presente trabalho analisa de forma geral todos os temas relacionados a poder na produção científica indexadas na base de dados SPELL nas áreas de administração, administração pública, contabilidade e turismo.

Quadro 1. Síntese dos trabalhos bibliométricos

\begin{tabular}{|c|c|c|c|}
\hline Autores (ano) & Objetivo geral & Metodologia & Resultados \\
\hline $\begin{array}{l}\text { Giglio, Pugliese e } \\
\text { Silva (2012) }\end{array}$ & $\begin{array}{l}\text { Discutir a presença } \\
\text { do poder nos } \\
\text { artigos sobre redes } \\
\text { de negócios. }\end{array}$ & $\begin{array}{l}\text { Análise teórica de artigos } \\
\text { publicados em } 22 \text { revistas } \\
\text { brasileiras classificadas } \\
\text { como qualis A2 pelos } \\
\text { critérios da CAPES. }\end{array}$ & $\begin{array}{l}\text { Verificou-se o número reduzido de artigos } \\
\text { brasileiros sobre a relação entre os temas poder } \\
\text { e redes. Foram encontrados artigos sobre } \\
\text { redes que tratam do poder, sem mencioná-lo } \\
\text { explicitamente, colocando outras palavras tais } \\
\text { como governança e assimetria. }\end{array}$ \\
\hline $\begin{array}{l}\text { Santos e Claro } \\
(2014)\end{array}$ & $\begin{array}{l}\text { Descrever } \\
\text { e analisar as } \\
\text { principais } \\
\text { características } \\
\text { da pesquisa em } \\
\text { Administração, } \\
\text { com ênfase nos } \\
\text { subtemas Poder } \\
\text { e Política nas } \\
\text { Organizações, à } \\
\text { luz do referencial } \\
\text { teórico das Teorias } \\
\text { Organizacionais. }\end{array}$ & $\begin{array}{l}\text { Base de dados constituída } \\
\text { de } 208 \text { artigos dos } \\
\text { Anais dos Encontros da } \\
\text { ANPAD (Associação } \\
\text { Nacional de Pós- } \\
\text { Graduação e Pesquisa } \\
\text { em Administração) no } \\
\text { período de } 2008 \text { a } 2013 \text {. } \\
\text { Estudo bibliométrico e } \\
\text { descritivo. }\end{array}$ & $\begin{array}{l}\text { Foi constatado que Poder e Política vêm } \\
\text { sendo tratados no âmbito das organizações } \\
\text { e que a pesquisa exploratória é a estratégia } \\
\text { metodológica mais utilizada. A complexidade } \\
\text { do tema sugere que } 80 \% \text { dos artigos foram } \\
\text { elaborados com a participação de dois } \\
\text { pesquisadores ou mais. }\end{array}$ \\
\hline
\end{tabular}




\begin{tabular}{|c|c|c|c|}
\hline $\begin{array}{l}\text { Oliveira, } \\
\text { Sacomano Neto } \\
\text { e Boaventura } \\
(2016)\end{array}$ & $\begin{array}{l}\text { Compreender } \\
\text { como as relações } \\
\text { de poder são } \\
\text { abordadas na } \\
\text { literatura. }\end{array}$ & $\begin{array}{l}\text { Utiliza como dados } 26 \\
\text { artigos da base Thomson } \\
\text { Reuters (ISI) Web of } \\
\text { Science de } 2003 \text { a } 2012 . \\
\text { Abordagem qualitativa. }\end{array}$ & $\begin{array}{l}\text { A análise das publicações selecionadas aponta } \\
\text { para a multiplicidade de perspectivas teóricas } \\
\text { na abordagem do poder na literatura e indica } \\
\text { um aumento do interesse no tema ao longo } \\
\text { do tempo. As principais perspectivas teóricas } \\
\text { identificadas são a Teoria da Dependência de } \\
\text { Recursos; a Teoria da Troca em Redes; e a } \\
\text { Teoria de Custos de Transação. }\end{array}$ \\
\hline
\end{tabular}

Fonte: Elaborado pelos autores (2017).

Giglio, Pugliese e Silva (2012) discutem a utilização dos conceitos de poder nos artigos sobre redes de negócios. Os autores partem do pressuposto que o tema do poder é raro nos artigos brasileiros, porque tem uma variável negativa em decorrência do paradigma cognitivo de alguns pesquisadores, que entendem as redes como sistemas de cooperação e confiança. Entretanto, baseado nos argumentos de autores clássicos, os autores afirmam a necessidade de incluir o poder nos estudos da Administração, em contraposição com a quase ausência do tema num levantamento bibliográfico das revistas brasileiras classificadas como A2. Os artigos sobre redes tratam do poder, sem mencioná-lo explicitamente, colocando outras palavras tais como governança e assimetria.

Santos e Claro (2014) analisaram as principais características da pesquisa em Administração, com ênfase nos subtemas Poder e Política nas Organizações. Os autores realizaram uma pesquisa bibliométrica e descritiva nos anais dos Encontros da ANPAD (Associação Nacional de Pós-Graduação e Pesquisa em Administração) no período de 2008 a 2013. Eles constataram que os temas poder e política vêm sendo tratados no âmbito das organizações e que a pesquisa exploratória é a estratégia metodológica mais utilizada.

Por último, a revisão sistemática de Oliveira, Sacomano Neto e Boaventura (2016) tem o objetivo de compreender como as relações de poder são abordadas na literatura, utilizando a base de dados Thomson Reuters (ISI) Web of Science. Os autores concluíram que os estudos em redes de negócios é um campo em construção e com uma marcada competição entre abordagens concorrentes. Eles verificaram a dominância da teoria da dependência de recursos nos estudos de redes, justificando a partir da correlação desta teoria com a origem das abordagens que coexistem nos estudos das redes.

\section{Metodologia}

Para que a questão de pesquisa fosse respondida de forma satisfatória, foi estabelecido previamente o procedimento metodológico a ser seguido neste estudo. Assim, este trabalho caracteriza-se pela reflexão da produção científica brasileira sobre poder e foi conduzido pelo método de pesquisa bibliométrico.

Para Otlet (1986), a medida é uma forma superior de enfoque em todos os campos do conhecimento e a bibliometria possibilita a formação de um conjunto coordenado de medidas que farão referência à objetos, fenômenos ou fatos de um documento. Macias-Chapula (1998) acrescenta que a bibliometria estuda os fatores quantitativos de uma pesquisa incluindo sua elaboração e propagação de informações registradas. Guedes e Borschiver (2005) definem a pesquisa bibliométrica como uma ferramenta que possibilita o exame e a inferência de indicadores de tratamento do conhecimento, necessários para a avaliação da ciência por uma comunidade científica.

Quanto ao objetivo desta investigação, a pesquisa classificou-se como pesquisa exploratória-descritiva. Acevedo e Nohara (2006, p. 46) retratam que o principal objetivo da pesquisa exploratória "é proporcionar maior compreensão do fenômeno que está sendo investigado, permitindo assim, que o pesquisador delineie de forma mais precisa o problema". Locke, Silverman e Spirduso (2010) comentam que a pesquisa descritiva visa conhecer o cenário de uma situação, expressando o resultado do fenômeno em números. 
Em relação à abordagem do problema, esta pesquisa classifica-se como quantitativa. A pesquisa quantitativa oferece a possibilidade de generalização dos resultados de forma mais ampla, com enfoque sobre pontos específicos e um panorama de contagem e magnitude em relação aos fenômenos. (SAMPIERI; COLLADO; LUCIO, 2013). Quanto aos procedimentos, utilizouse de pesquisa documental dos periódicos publicados no período de 2006 a 2015, obtidos mediante consulta ao banco de dados SPELL (Scientific Periodicals Eletronic Library).

Inicialmente, realizou-se a coleta de artigos publicados no banco de dados do portal de periódicos SPELL, considerado como um repositório de artigos científicos que proporciona acesso à informação técnico-científica concentrada nas áreas de Administração, Administração Pública, Contabilidade e Turismo. Os artigos foram selecionados utilizando a pesquisa avançada.

A busca foi efetuada colocando o termo "poder" nos campos "título do documento" e "palavra-chave". O período de publicação delimitado foi de janeiro de 2006 a dezembro de 2016. Por fim, foi selecionado o item artigo nos tipos de documento e foram marcadas as áreas de conhecimento: administração, administração pública, contabilidade e turismo. Nessas configurações, a busca retornou 247 resultados. A pesquisa do termo "poder" no campo "resumo" foi desconsiderada, pois selecionava muitos artigos fora da temática em virtude das variações da forma verbal.

Depois da seleção dos artigos, procedeu-se a leitura dos mesmos, excluindo os artigos que não estudavam o fenômeno poder, restando uma amostra de 158 artigos. Em muitos dos artigos excluídos o termo poder estava associado à constructos referentes à organização política como: legislativo, municipal, executivo, sendo desconsiderados por não estar alinhados com o objetivo desse estudo.

Em seguida, os dados foram tabulados numa planilha elaborada no programa Microsoft Excel versão 16.0, com roteiro estruturado, conforme os objetivos específicos, com os seguintes itens: título do artigo, identificação da revista, ano de publicação, tema central, procedimentos metodológicos (classificação se teórico ou empírico, quanto à abordagem, quanto aos procedimentos, quanto aos objetivos, técnica de coleta e método de análise de dados), campo/setor de estudo e perfil do(s) autor(es) (nome, formação, instituição).

Com relação à identificação da instituição do autor, o critério utilizado para a triagem dos dados informados no artigo segue a ordem dos quesitos: (1) a instituição que o pesquisador trabalha ou estuda; (2) a instituição onde foi formado ou (3) não especificado. $\mathrm{Na}$ quantificação da formação e da instituição do autor não foram excluídos os autores que se repetiam, pois verificou-se que a depender da data de publicação do artigo, esses dados apresentavam diferenças.

O método de análise de dados utilizado foi a análise de conteúdo. A análise dos dados compõe uma técnica de análise de conteúdo por temas, que consiste em aproveitar partes isoladas de um texto, conforme o problema observado, possibilitando a sua comparação com outros textos selecionados da mesma maneira. Este tipo de análise se dá através de categorias com a finalidade de constituir elementos proeminentes da teoria (MOZZATO; GRZYBOVSKI, 2011). Segundo Chizzotti (2006), a análise de conteúdo consiste em interpretar o conteúdo de um texto desenvolvido, que adotou normas sistemáticas de extrair os significados temáticos por meio de seus elementos.

\section{Resultados}

Os resultados do presente trabalho foram expostos a seguir, de acordo com os objetivos especificados para análise: (1) verificar a evolução da produção científica; (2) identificar os eixos temáticos; (3) identificar os procedimentos metodológicos adotados; (4) identificar os campos ou setores mais estudados e (5) identificar o perfil de autoria.

\section{Dinâmica da produção científica}

Nesta seção analisa-se a dinâmica da produção científica no período de 2006 a 2016. Na tabela 1 são listados os periódicos que publicaram sobre a temática e no gráfico 1 está a quantidade de artigos publicados por ano.

A Tabela 1 apresenta a quantidade de artigos publicados por periódico. Foram 158 artigos publicados em 58 revistas. Os periódicos que mais publicaram foram: Cadernos EBAPE.BR, Revista de Administração Pública, GESTÃO.Org - Revista Eletrônica de Gestão Organizacional e Organizações \& Sociedade, com 21, 11, 9 e 8 artigos, respectivamente. Isso é um indicativo da importância do tema e do interesse da comunidade científica sobre ele. De acordo com Kich et al. (2012), o poder é um assunto de grande complexidade, possuindo uma grande variedade de estudos a respeito. 
Tabela 1. Quantidade de artigos publicados por periódico

\begin{tabular}{|c|c|c|c|c|c|c|c|c|c|c|c|c|}
\hline Identificação da revista & ષ્ڤે & ક్ & $\stackrel{\text { ¿े }}{\infty}$ & ڤ్రે & 옥 & $\overline{\text { సे }}$ & స్ & ڤี & 芯 & $\stackrel{\sim}{\text { กิ }}$ & ڤั่ & 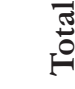 \\
\hline Cadernos EBAPE.BR & 3 & 2 & 2 & 1 & 4 & 2 & 1 & 2 & 1 & 2 & 1 & 21 \\
\hline Revista de Administração Pública & & & 1 & 2 & 2 & 1 & 1 & 1 & 2 & 1 & & 11 \\
\hline GESTÃO.Org - R. Eletr. de Gestão Organizacional & 3 & 1 & & & & & 2 & & 3 & & & 9 \\
\hline Organizações \& Sociedade & 1 & 1 & 1 & 1 & 1 & 1 & 1 & 1 & & & & 8 \\
\hline Revista de Administração Mackenzie & & & & & 2 & 1 & 1 & 1 & 1 & & & 6 \\
\hline Revista Gestão \& Planejamento & & & & & 1 & & 1 & 2 & & 1 & 1 & 6 \\
\hline Revista de Administração FACES Journal & & & 1 & & & 1 & 1 & 1 & & & 2 & 6 \\
\hline Revista de Administração & 1 & & & & 1 & & 1 & & 1 & & 1 & 5 \\
\hline Revista Pensamento Contemporâneo em Administração & & & & & & & & 1 & & 2 & 2 & 5 \\
\hline Revista de Administração Contemporânea & 1 & & & & 2 & & & & & & 1 & 4 \\
\hline Administração Pública e Gestão Social & & & & & & 1 & 2 & & & & & 3 \\
\hline Cadernos Gestão Pública e Cidadania & & 1 & & 2 & & & & & & & & 3 \\
\hline Revista Alcance & 1 & & & 1 & & 1 & & & & & & 3 \\
\hline Revista de Administração de Empresas & & & & & & 1 & & & 1 & 1 & & 3 \\
\hline Revista de Ciências da Administração & & & & & 1 & & & & 1 & 1 & & 3 \\
\hline Revista Pretexto & & & & & & & 1 & 1 & & 1 & & 3 \\
\hline Teoria e Prática em Administração & & & & & & & 1 & & 1 & 1 & & 3 \\
\hline Revista de Administração da UFSM & & & & 1 & 1 & & & & & & 1 & 3 \\
\hline REAd. Revista Eletrônica de Administração & & & & & 1 & 1 & & & & & 1 & 3 \\
\hline Contabilidade, Gestão e Governança & & & & & & & 1 & & & 1 & & 2 \\
\hline Gestão e Sociedade & & & & & & & 1 & & & 1 & & 2 \\
\hline Interface - R. do Centro de Ciências Sociais Aplicadas & & & & & & 1 & & 1 & & & & 2 \\
\hline Organizações Rurais \& Agroindustriais & & & & 1 & & & & & & 1 & & 2 \\
\hline RACE: R. de Adm., Contabilidade e Economia & & & & 1 & & & & & 1 & & & 2 \\
\hline Revista Administração em Diálogo & & & 1 & & 1 & & & & & & & 2 \\
\hline Revista Capital Científico - Eletrônica & & & & & & & 1 & 1 & & & & 2 \\
\hline Revista Universo Contábil & & & & & 1 & & & & & 1 & & 2 \\
\hline Sociedade, Contabilidade e Gestão & & 1 & & & & & & & & 1 & & 2 \\
\hline Revista ADM.MADE & & & & 1 & & 1 & & & & & & 2 \\
\hline Periódicos com apenas 01 publicação no período & & & & & & & & & & & & 28 \\
\hline Total (58 revistas) & $=$ & r & $\stackrel{?}{ح}$ & 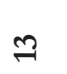 & กิ & $\stackrel{2}{\Omega}$ & กิ & $\simeq$ & $\exists$ & 2 & $\approx$ & $\stackrel{\infty}{+}$ \\
\hline
\end{tabular}

Fonte: Elaborado pelos autores a partir de dados da pesquisa (2017).

O gráfico 1 mostra que houve uma flutuação na produção científica. Constata-se que os anos de maior produtividade foram 2010 e 2012 com 20 artigos cada um, seguido por 2015 com 19. O ano de 2007 foi o menos produtivo do período com um total de 7 artigos. Santos e Claro (2014) constataram que os artigos publicados nos anais do EnANPAD no período de 2008 a 2013 oscilam de 10 a 15. Os dados da presente pesquisa apontam resultados semelhantes, sendo que os anos de 2010, 2012 e 2015 ficaram acima de 15 e o ano de 2007 abaixo de 10. 
Gráfico 1. Quantidade de artigos publicados por ano

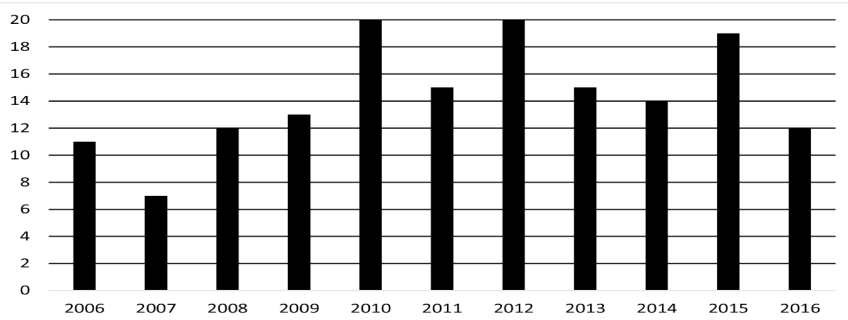

Fonte: Elaborado pelos autores a partir de dados da pesquisa (2017).

Da análise da dinâmica da produção científica no período de 2006 a 2016, evidencia-se que a produção científica sobre poder nesses 11 anos é significativa, com períodos de ascensão e declínio, sendo um tema amplamente discutido nas ciências sociais (CAPPELLE; MELO; BRITO, 2005). Verifica-se também um gradual interesse no tema ao longo do tempo, conforme apontado por Oliveira, Sacomano Neto e Boaventura (2016).

\section{Eixos temáticos}

$\mathrm{Na}$ Tabela 2, são classificados os temas abordados pelos artigos analisados.

Tabela 2 . Eixos temáticos

\begin{tabular}{|c|c|c|c|}
\hline Ordem & Tema central & $\begin{array}{l}\text { Quantidade de } \\
\text { artigos }\end{array}$ & $\%$ \\
\hline 1 & Relações & 25 & 15,8 \\
\hline 2 & Redes & 9 & 5,7 \\
\hline 3 & Conhecimento & 8 & 5,1 \\
\hline 4 & Gênero & 7 & 4,4 \\
\hline 5 & Controle & 6 & 3,8 \\
\hline 6 & Cultura & 6 & 3,8 \\
\hline 7 & Liderança & 6 & 3,8 \\
\hline 8 & Estratégia & 6 & 3,8 \\
\hline 9 & Institucionalização & 5 & 3,2 \\
\hline 10 & Mudança & 4 & 2,5 \\
\hline 11 & Discurso & 4 & 2,5 \\
\hline 12 & Espaço & 4 & 2,5 \\
\hline 13 & Gestão de pessoas & 4 & 2,5 \\
\hline 14 & Gestão social & 4 & 2,5 \\
\hline 15 & Empreendedorismo & 4 & 2,5 \\
\hline 16 & Comunicação & 3 & 1,9 \\
\hline 17 & Emoções & 3 & 1,9 \\
\hline 18 & Governança & 3 & 1,9 \\
\hline 19 & Política & 3 & 1,9 \\
\hline
\end{tabular}

20

$$
\begin{aligned}
& \text { Tecnologia da } \\
& \text { informação }
\end{aligned}
$$

Outros temas 3

41

Fonte: Elaborado pelos autores a partir de dados da pesquisa (2017).

Percebe-se a grande quantidade de temas e sua variabilidade. O tema que se destaca é o relacionamento entre os atores e organizações com $15,8 \%$ da produção do período analisado. Nota-se uma grande diferença na quantidade de artigos quando comparado com os demais. Os outros temas mais representativos são: redes, com $5,7 \%$; conhecimento, com $5,1 \%$; gênero, com 4,4\%; controle, cultura, liderança e estratégia, com 3,8\% cada; e, por fim, institucionalização, com $3,2 \%$. Esses nove temas correspondem a $49,4 \%$ da produção analisada.

Observa-se que os temas mais abordados foram objeto de estudos bibliométricos. O primeiro, relações de poder, foi estudado por Oliveira, Sacomano Neto e Boaventura (2016). Já o segundo, redes, foi analisado por Giglio, Pugliese e Silva (2012). Entretanto, nota-se também uma quantidade significativa de outros temas como conhecimento e gênero, apontado por Hardy e Clegg (2001). Os resultados mostram a variedade de eixos temáticos relacionados com o poder. Destacase que o tema política, estudado por Santos e Claro (2014), teve representatividade de apenas 1,9\% dos artigos pesquisados. Esse fato pode estar associado ao tabu em torno dos temas por parte dos investigadores organizacionais (MIRANDA, 2008).

\section{Procedimentos metodológicos}

No que se refere à análise dos procedimentos metodológicos, primeiramente os artigos foram classificados como teórico e empírico. De acordo com Demo (1985), a pesquisa teórica é aquela que monta e desvenda quadros de referência, reconstruindo conceitos, ideias, ideologias, polêmicas, etc. A pesquisa empírica, por sua vez, traz a teoria para a realidade concreta, voltando-se para a face experimental e observável dos fenômenos. Da totalidade dos artigos analisados 36,1\% são teóricos e 63,9\% são empíricos (veja Tabela 3). Assim, evidencia-se que o poder é mais estudado na realidade prática. Esse fato pode estar relacionado às suas formas diferentes de manifestação que propicia diversos modos de observação e análise (FISCHER, 2001). 
Tabela 3 . Classificação quanto ao tipo de pesquisa

\begin{tabular}{lll}
\hline $\begin{array}{l}\text { Classificação quanto ao } \\
\text { tipo de pesquisa }\end{array}$ & $\begin{array}{l}\text { Quantidade de } \\
\text { artigos }\end{array}$ & $\mathbf{\%}$ \\
\hline Teórico & 57 & 36,1 \\
Empírico & 101 & 63,9 \\
\hline
\end{tabular}

Fonte: Elaborado pelos autores a partir de dados da pesquisa (2017).

A metodologia dos artigos empíricos foi analisada. A tabela 4 mostra o delineamento dessas pesquisas. Com relação à abordagem, nota-se a predominância de estudos qualitativos, correspondendo a $68,3 \%$. Os estudos quantitativos equivalem a $9,9 \%$ e os que utilizam as duas abordagens, qualitativa e quantitativa, a 3,0\%. A preferência pela metodologia qualitativa pode estar associada ao fato dela possibilitar descrever a complexidade de determinado problema, compreender processos dinâmicos vividos por grupos sociais e proporcionar o entendimento das particularidades do comportamento dos indivíduos (RICHARDSON et al., 2015). Dessa maneira, ela se mostra adequada para o estudo do poder. Entretanto, faz-se necessário utilizar outras formas, realizando pesquisas com outras abordagens (quantitativa ou métodos mistos).

Quanto aos procedimentos, o estudo de caso foi utilizado em 42,6\% dos trabalhos, sendo o método predominante. Santos e Claro (2014) e Oliveira, Sacomano Neto e Boaventura (2016) constataram a importância do estudo de caso como procedimento no desenvolvimento das pesquisas sobre poder. O resultado encontrado corrobora com o desses estudos. Outros métodos utilizados foram: pesquisa de campo, etnografia, survey, história de vida, pesquisa bibliográfica, pesquisa documental e levantamento. Percebe-se a variedade de procedimentos de pesquisa qualitativa nos estudos sobre poder.

Em relação à classificação das pesquisas quanto aos objetivos, os autores não especificaram em grande parte dos artigos (55,4\%). Dos artigos especificados, $22,8 \%$ são de natureza descritiva, 10,9\% exploratória, $8,9 \%$ exploratória e descritiva, $1,0 \%$ descritiva e explicativa e 1,0\% explicativa. Esse resultado diverge do encontrado por Santos e Claro (2014) que constataram a predominância de estudos exploratórios para essa temática.
Tabela 4 . Delineamento da metodologia dos artigos pesquisados

\begin{tabular}{|c|c|c|}
\hline $\begin{array}{l}\text { Classificação } \\
\text { quanto à } \\
\text { abordagem } \\
\end{array}$ & $\begin{array}{l}\text { Quantidade de } \\
\text { artigos }\end{array}$ & $\%$ \\
\hline Qualitativa & 69 & 68,3 \\
\hline Quantitativa & 10 & 9,9 \\
\hline $\begin{array}{l}\text { Qualitativa e } \\
\text { quantitativa }\end{array}$ & 3 & 3,0 \\
\hline $\begin{array}{l}\text { Não especificado no } \\
\text { artigo }\end{array}$ & 19 & 18,8 \\
\hline $\begin{array}{l}\text { Classificação } \\
\text { quanto aos } \\
\text { procedimentos }\end{array}$ & $\begin{array}{l}\text { Quantidade de } \\
\text { artigos }\end{array}$ & $\%$ \\
\hline Estudo de caso & 43 & 42,6 \\
\hline Pesquisa de campo & 6 & 5,9 \\
\hline Etnografia & 3 & 3,0 \\
\hline Survey & 3 & 3,0 \\
\hline História de vida & 2 & 2,0 \\
\hline $\begin{array}{l}\text { Pesquisa bibliográfica } \\
\text { e de campo }\end{array}$ & 2 & 2,0 \\
\hline Pesquisa documental & 2 & 2,0 \\
\hline Levantamento & 1 & 1,0 \\
\hline Pesquisa bibliográfica & 1 & 1,0 \\
\hline $\begin{array}{l}\text { Pesquisa } \\
\text { bibliográfica, } \\
\text { documental e de } \\
\text { campo }\end{array}$ & 1 & 1,0 \\
\hline $\begin{array}{l}\text { Não especificado no } \\
\text { artigo }\end{array}$ & 37 & 36,6 \\
\hline $\begin{array}{l}\text { Classificação } \\
\text { quanto aos } \\
\text { objetivos }\end{array}$ & $\begin{array}{l}\text { Quantidade de } \\
\text { artigos }\end{array}$ & $\%$ \\
\hline Pesquisa descritiva & 23 & 22,8 \\
\hline Pesquisa exploratória & 11 & 10,9 \\
\hline $\begin{array}{l}\text { Pesquisa exploratória } \\
\text { e descritiva }\end{array}$ & 9 & 8,9 \\
\hline $\begin{array}{l}\text { Pesquisa descritiva e } \\
\text { explicativa }\end{array}$ & 1 & 1,0 \\
\hline Pesquisa explicativa & 1 & 1,0 \\
\hline $\begin{array}{l}\text { Não especificado no } \\
\text { artigo }\end{array}$ & 56 & 55,4 \\
\hline
\end{tabular}

Fonte: Elaborado pelos autores a partir de dados da pesquisa (2017).

Em seguida, as técnicas de coleta e de análise de dados foram examinadas. Ressalta-se que essa parte não foi realizada pelos estudos bibliométricos anteriores. De acordo com a tabela 5, a entrevista foi a técnica de coleta mais utilizada, sozinha ou em combinação com 
outras. Os métodos predominantes foram: somente entrevista $(29,7 \%)$, dados secundários $(14,9 \%)$ e entrevista e dados secundários (11,9\%). Observação, questionário, desenho, diário de campo, dinâmica de grupo e grupo focal foram outros métodos também empregados. Nota-se a variedade de técnicas, assim como a combinação delas nos trabalhos.

Tabela 5 . Técnicas de coleta de dados dos artigos pesquisados

\begin{tabular}{lll}
\hline $\begin{array}{l}\text { Técnicas de coleta de } \\
\text { dados }\end{array}$ & $\begin{array}{l}\text { Quantidade de } \\
\text { artigos }\end{array}$ & $\mathbf{\%}$ \\
\hline Entrevista & 30 & 29,7 \\
$\begin{array}{l}\text { Dados secundários } \\
\text { Entrevista e dados }\end{array}$ & 15 & 14,9 \\
secundários & 12 & 11,9 \\
$\begin{array}{l}\text { Entrevista, dados } \\
\text { secundários e observação }\end{array}$ & 11 & 10,9 \\
$\begin{array}{l}\text { Questionário } \\
\text { Entrevista e observação }\end{array}$ & 10 & 9,9 \\
$\begin{array}{l}\text { Observação } \\
\text { Entrevista e questionário }\end{array}$ & 2 & 7,9 \\
$\begin{array}{l}\text { Desenho } \\
\text { Entrevista e diário de }\end{array}$ & 1 & 5,0 \\
campo & 1 & 2,0 \\
$\begin{array}{l}\text { Entrevista e dinâmica de } \\
\text { grupo }\end{array}$ & 1 & 1,0 \\
$\begin{array}{l}\text { Entrevista, dados } \\
\text { secundários e questionário }\end{array}$ & 1 & 1,0 \\
$\begin{array}{l}\text { Entrevista, dados } \\
\text { secundários, observação e }\end{array}$ & 1 & 1,0 \\
$\begin{array}{l}\text { questionário } \\
\text { Entrevista, observação e } \\
\text { grupo focal }\end{array}$ & 1 & 1,0 \\
$\begin{array}{l}\text { Entrevista, observação e } \\
\text { questionário }\end{array}$ & 1 & 1,0 \\
\begin{tabular}{l} 
Grupo focal \\
\hline
\end{tabular} & 1 & \\
\hline
\end{tabular}

Fonte: Elaborado pelos autores a partir de dados da pesquisa (2017).

No que se refere aos métodos de análise de dados, sobressaíram-se as técnicas análise de conteúdo $(27,7 \%)$, análise do discurso $(11,9 \%)$ e análise interpretativa $(3,0 \%)$ na perspectiva qualitativa. Com relação à perspectiva quantitativa, a análise de correlação foi a mais utilizada sozinha $(2,0 \%)$ e com outros métodos (estatística descritiva, análise bivariada, análise fatorial, ANOVA e regressão). Evidencia-se a variedade de técnicas de análise de dados qualitativos e quantitativos, bem como a combinação dessas técnicas (ver tabela 6).

Tabela 6 . Métodos de análise de dados dos artigos pesquisados

\begin{tabular}{ccc}
\hline $\begin{array}{c}\text { Método de análise de } \\
\text { dados }\end{array}$ & $\begin{array}{c}\text { Quantidade de } \\
\text { artigos }\end{array}$ & $\%$ \\
\hline
\end{tabular}

Análise qualitativa

Análise de conteúdo 27,7

Análise do discurso

28

Análise interpretativa

12

Análise argumentativa

Análise crítica do discurso

Análise crítica do

discurso e análise

retórica

Análise de combinação

sistemática

Análise de conteúdo

e de técnicas de

enunciação

Análise de narrativas

Análise de redes sociais

Análise de Spink

Análise de Spradley

Análise documental

Análise documental e

análise de conteúdo

Análise temática

Fundamentação nas

proposições teóricas

Método de

categorização dos dados

Método de Maguire,

Hardy e Lawrence

Técnica de síntese de

casos cruzados

Análise linguística do

discurso e Diferencial

1,0

Semântico

\begin{tabular}{lcc}
\hline Análise quantitativa & & \\
\hline $\begin{array}{l}\text { Análise de correlação } \\
\text { Análise exploratória de } \\
\text { dados, de dependência e } \\
\text { de igualdade de médias }\end{array}$ & 2 & 1,0 \\
$\begin{array}{l}\text { Análise fatorial } \\
\text { Estatística descritiva, } \\
\text { análise bivariada e }\end{array}$ & 1 & 1,0 \\
$\begin{array}{l}\text { correlação } \\
\text { Estatística descritiva, } \\
\text { análise fatorial, } \\
\text { correlação e ANOVA } \\
\begin{array}{l}\text { Estatística descritiva, } \\
\text { correlação e regressão }\end{array}\end{array}$ & 1 & 2,0 \\
\end{tabular}


Modelagem de

Equações Estruturais

Regressão

Análises qualitativa e

quantitativa

Análise de conteúdo e

modelagem de equações

estruturais

Análise de conteúdo, análise descritivo-

interpretativa e

estatística descritiva

Análise de conteúdo, estatística descritiva, análise bivariada e

correlação

Não especificado no

artigo

30

1

1,0

1,0

1,0

1

Fonte: Elaborado pelos autores a partir de dados da pesquisa (2017).

Em resumo, os procedimentos metodológicos predominantemente adotados nos trabalhos empíricos foram: abordagem qualitativa, utilizando a estratégia estudo de caso, com fins descritivos. A técnica de coleta de dados usada com mais frequência foi a entrevista e para analisá-los o método de análise de conteúdo. Destaca-se a diversidade de delineamentos de pesquisa, assim como de técnicas de coleta e análise de dados. Esse fato pode estar associado à complexidade do fenômeno poder (KICH et al., 2012; SANTOS; CLARO, 2014) e a necessidade de triangulação dos dados para conferir maior confiabilidade na pesquisa (GRAY, 2012).

\section{Campos ou setores mais estudados}

Os campos mais estudados nas publicações analisadas foram as instituições de ensino superior com 11 artigos. A elas se seguiram os seguintes: administração pública (9), cultura (7) e comércio (6) (veja Tabela 7). Outros campos analisados foram: banco, economia solidária, terceiro setor, agronegócio, tecnologia da informação, cooperativa, energia, espaço urbano, indústria, polícia militar, saúde, líderes, alimentos, assistência social, construção civil, mineração, organização familiar, serviços e transporte. Do exposto, observa-se que além da multiplicidade de temas e procedimentos metodológicos, há também uma variedade de setores estudados, demonstrando que o poder é permeável, está em todos os lugares e pode ser explorado sob diversos ângulos (KICH et al., 2012).
Tabela 7 . Campos ou setores mais estudados

\begin{tabular}{|c|c|c|}
\hline Ordem & Campo/setor & $\begin{array}{l}\text { Quantidade de } \\
\text { artigos }\end{array}$ \\
\hline 1 & $\begin{array}{l}\text { Instituições de ensino } \\
\text { superior }\end{array}$ & 11 \\
\hline 2 & Administração pública & 9 \\
\hline 3 & Cultura & 7 \\
\hline 4 & Comércio & 6 \\
\hline 5 & Banco & 5 \\
\hline 6 & Economia solidária & 5 \\
\hline 7 & Terceiro setor & 5 \\
\hline 8 & Agronegócio & 5 \\
\hline 9 & $\begin{array}{l}\text { Tecnologia da } \\
\text { informação }\end{array}$ & 4 \\
\hline 10 & Cooperativa & 4 \\
\hline 11 & Energia & 3 \\
\hline 12 & Espaço urbano & 3 \\
\hline 13 & Indústria & 3 \\
\hline 14 & Polícia militar & 3 \\
\hline 15 & Saúde & 3 \\
\hline 16 & Líderes & 3 \\
\hline 17 & Alimentos & 2 \\
\hline 18 & Assistência Social & 2 \\
\hline 19 & Construção civil & 2 \\
\hline 20 & Mineração & 2 \\
\hline 21 & Organização familiar & 2 \\
\hline 22 & Serviços & 2 \\
\hline \multirow[t]{2}{*}{23} & Transporte & 2 \\
\hline & Outros setores & 15 \\
\hline
\end{tabular}

Fonte: Elaborado pelos autores a partir de dados da pesquisa (2017).

\section{Perfil de autoria}

Para a definição do perfil de autoria, levou-se em consideração o nome de todos os autores dos artigos da amostra pesquisada. Observa-se que os estudos foram realizados por no máximo seis pesquisadores, sendo que o número predominante foi de dois autores por artigo, equivalendo a $37,3 \%$, seguido pela quantidade de três autores, com $31,0 \%$ dos trabalhos (conforme Tabela 8).

A porcentagem de estudos efetuados por um e por quatro autores é de 14,6\% cada. Por último, os trabalhos com 5 e 6 autores são inexpressivos, equivalendo a $1,9 \%$ e $0,6 \%$ respectivamente. Santos e Claro (2014) apontam a participação de dois ou mais pesquisadores nas pesquisas sobre o poder como consequência da complexidade do tema. Os resultados dessa pesquisa são semelhantes ao encontrado por esses autores. 
Tabela 8 . Quantidade de autores por artigo

\begin{tabular}{lll}
\hline $\begin{array}{l}\text { Quantidade de } \\
\text { autores }\end{array}$ & $\begin{array}{l}\text { Quantidade } \\
\text { de artigos }\end{array}$ & \% \\
\hline 1 autor & 23 & 14,6 \\
2 autores & 59 & 37,3 \\
3 autores & 49 & 31,0 \\
4 autores & 23 & 14,6 \\
5 autores & 3 & 1,9 \\
6 autores & 1 & 0,6 \\
\hline
\end{tabular}

Fonte: Elaborado pelos autores a partir de dados da pesquisa (2017).

Com relação à produção dos autores, verifica-se que dos 390 autores/coautores, os mais produtivos no período foram: Alexandre de Pádua Carrieri e Marcelo Milano Falcão Vieira, com seis artigos cada; Fernando Coutinho Garcia, com cinco; e, José Henrique de Faria, Marlene Catarina de Oliveira Lopes Melo e Eloisio Moulin de Souza, com quatro artigos cada (conforme Tabela 9). O autor José Henrique de Faria já havia sido apontado por Santos e Claro (2014) como um autor produtivo nessa temática.

Tabela 9 . Autores mais produtivos

\begin{tabular}{|c|c|c|c|}
\hline Ordem & Autor & Instituição & $\begin{array}{l}\mathrm{N}^{\circ} \text { de } \\
\text { artigos }\end{array}$ \\
\hline 1 & $\begin{array}{l}\text { Alexandre de } \\
\text { Pádua Carrieri }\end{array}$ & $\begin{array}{l}\text { Universidade } \\
\text { Federal de } \\
\text { Minas Gerais }\end{array}$ & 6 \\
\hline 2 & $\begin{array}{l}\text { Marcelo } \\
\text { Milano Falcão } \\
\text { Vieira }\end{array}$ & EBAPE/FGV & 6 \\
\hline 3 & $\begin{array}{l}\text { Fernando } \\
\text { Coutinho } \\
\text { Garcia }\end{array}$ & $\begin{array}{l}\text { Faculdade } \\
\text { Novos } \\
\text { Horizontes }\end{array}$ & 5 \\
\hline 4 & $\begin{array}{l}\text { José Henrique } \\
\text { de Faria }\end{array}$ & $\begin{array}{l}\text { Universidade } \\
\text { Federal do } \\
\text { Paraná }\end{array}$ & 4 \\
\hline 5 & $\begin{array}{l}\text { Marlene } \\
\text { Catarina de } \\
\text { Oliveira Lopes } \\
\text { Melo }\end{array}$ & $\begin{array}{l}\text { Faculdade } \\
\text { Novos } \\
\text { Horizontes }\end{array}$ & 4 \\
\hline 6 & $\begin{array}{l}\text { Eloisio Moulin } \\
\text { de Souza }\end{array}$ & $\begin{array}{l}\text { Universidade } \\
\text { Federal do } \\
\text { Espírito Santo }\end{array}$ & 4 \\
\hline
\end{tabular}

Fonte: Elaborado pelos autores a partir de dados da pesquisa (2017).
$\mathrm{Na}$ Tabela 10, apresenta-se a formação dos autores. Constata-se a amplitude do grau de formação, que varia de graduando a pós-doutor. Verifica-se a predominância de pesquisadores com o grau de doutor $(32,1 \%)$, seguido por mestres $(11,5 \%)$ e doutorandos $(10,3 \%)$. O grande número de publicações por doutores pode estar associada à complexidade do tema, que exige um maior aprofundamento teórico.

Tabela 10 . Formação dos autores

\begin{tabular}{|c|c|c|}
\hline Formação & $\begin{array}{l}\text { Quantidade de } \\
\text { autores }\end{array}$ & $\%$ \\
\hline Doutorado & 125 & 32,1 \\
\hline Mestrado & 45 & 11,5 \\
\hline Doutorando & 40 & 10,3 \\
\hline Pós-doutorado & 18 & 4,6 \\
\hline Mestrando & 15 & 3,8 \\
\hline Graduado & 9 & 2,3 \\
\hline Graduando & 2 & 0,5 \\
\hline $\begin{array}{l}\text { Não especificado no } \\
\text { artigo }\end{array}$ & 136 & 34,9 \\
\hline
\end{tabular}

Fonte: Elaborado pelos autores a partir de dados da pesquisa (2017).

$\mathrm{Na}$ Tabela 8, são listadas as instituições as quais os autores estão vinculados. As cinco universidades com mais autores que publicaram foram: Escola Brasileira de Administração Pública e de Empresas - FGV, Universidade Federal de Minas Gerais, Faculdade Novos Horizontes e Universidade de São Paulo. Todas essas instituições são da região sudeste. Assim, constata-se que esse tema tem sido mais estudado por pesquisadores do sudeste, podendo ser mais explorado por pesquisadores de outras regiões do Brasil.

Tabela 8 . Instituições dos autores

\begin{tabular}{ll}
\hline Instituição & $\begin{array}{l}\text { Quantidade de } \\
\text { autores }\end{array}$ \\
\hline $\begin{array}{l}\text { Escola Brasileira de } \\
\text { Administração Pública e de }\end{array}$ & 28 \\
$\begin{array}{l}\text { Empresas - FGV } \\
\text { Universidade Federal de Minas }\end{array}$ & 25 \\
Gerais & 18 \\
Faculdade Novos Horizontes & 17 \\
Universidade de São Paulo & 17
\end{tabular}


Universidade Federal de Santa

Catarina

Universidade Federal de Lavras 1

Universidade Estadual de

Maringá

Universidade Federal do

Espírito Santo

Universidade Federal de

Pernambuco

Universidade Federal do Paraná

Pontifícia Universidade Católica

de Minas Gerais

Escola de Administração de

Empresas de São Paulo - FGV

Universidade Federal de Juiz de

Fora

Universidade Federal do Rio de

Janeiro

Universidade Federal de São

Carlos

Pontifícia Universidade Católica

do Rio de Janeiro

Pontifícia Universidade Católica

de São Paulo

Universidade Federal de Santa

Maria

Universidade Municipal de São

Caetano do Sul

Universidade do Oeste de Santa 5

Catarina

Universidade Federal do Rio

Grande do Norte

Universidade Federal do Rio

Grande do Sul

Universidade Federal da Paraíba 5

Aalto University Design Factory 4

Universidade do Extremo Sul

Catarinense

Universidade Estadual de

Londrina

Universidade Federal de Viçosa 4

Universidade Federal Rural do

Rio de Janeiro

Universidade Federal Rural do

Semi-Árido

Universidade de Caxias do Sul

(UCS)

Não especificado no artigo 9

Universidades com menos de

03 autores

60

Fonte: Elaborado pelos autores a partir de dados da pesquisa (2017). 
também com outras menos exploradas como gestão de pessoas, empreendedorismo, comunicação, etc.

O terceiro objetivo específico foi identificar os procedimentos metodológicos adotados. A hipótese era que os estudos seriam de abordagem qualitativa, com procedimento estudo de caso, de natureza exploratória, utilizando como método de coleta a entrevista e para a análise dos dados a de conteúdo. Essa hipótese foi parcialmente confirmada, uma vez que constatou-se a predominância de artigos de natureza descritiva e não de caráter exploratório. Entretanto, destaca-se que grande parte dos artigos não especificaram sua classificação quanto aos objetivos. Com relação ao estudo de caso, o resultado encontrado é semelhante ao das pesquisas de Santos e Claro (2014) e Oliveira, Sacomano Neto e Boaventura (2016). Conclui-se que os estudos são predominantemente qualitativos, porém para que a pesquisa nesse campo avance é necessário também que sejam realizados estudos com abordagens diferentes como quantitativas ou mistas.

O quarto objetivo específico foi identificar os campos ou setores mais estudados. As instituições de ensino superior, a administração pública, a cultura, os bancos e o comércio foram os principais setores pesquisados nas publicações analisadas. Sendo assim, a quinta hipótese, que o setor mais estudado são as instituições de ensino superior, foi confirmada. Observou-se também a variedade de setores que os trabalhos empíricos pesquisaram, demonstrando a presença do fenômeno em diversas organizações.

Por fim, o quinto objetivo específico foi identificar o perfil de autoria. A hipótese cinco formulada era que as pesquisas foram realizadas por três autores, doutores e vinculados à universidades da região sudeste. Essa hipótese foi parcialmente confirmada, visto que o único critério que não houve convergência foi com o resultado do número de autores por artigo que predominantemente são dois. Foi identificado também que Alexandre de Pádua Carrieri e Marcelo Milano Falcão Vieira são os autores mais produtivos. De acordo com esse resultado, percebe-se que ainda há muito o que ser pesquisado dessa temática em outras regiões do Brasil.

Ressalta-se que o poder pode assumir facetas diferentes de acordo com as variedades regionais, sendo que pesquisas nesse sentido ampliariam o campo de estudo do fenômeno.

A presente pesquisa apresenta como contribuição uma análise quantitativa das publicações sobre poder nas áreas de administração, administração pública, contabilidade e turismo, enfocando a evolução da produção científica, os temas recorrentes, os procedimentos metodológicos adotados, os setores mais pesquisados e o perfil de autoria.

Foi realizado um estudo englobando a diversidade de eixos temáticos relacionados ao poder, fornecendo um panorama da produção acadêmica nessas áreas nos últimos 11 anos. Com base nos resultados, fazse sugestões para diversificar o estudo do poder, apontando temas, setores e metodologias que estão sendo menos exploradas e precisem de mais atenção. Sendo assim, esse trabalho contribui para o estudo do poder por mostrar os limites do campo e onde precisa ser melhor desenvolvido, representando um avanço para estas áreas de estudo.

Ressalta-se a amplitude e significância dessa produção. Estudar o fenômeno poder é de grande importância para o ser humano em suas esferas de atuação, uma vez que ele faz parte dos padrões culturais vigentes, atingindo diferentes agentes e sendo por eles manipulado para atingir seus interesses (FISCHER, 1989).

O estudo apresenta como limitação o fato de analisar a produção científica indexada apenas em uma base de dados. Recomenda-se replicar esse estudo com outras bases, assim como em anais dos eventos da Associação Nacional de Pós-Graduação e Pesquisa em Administração (ANPAD).

\section{Referências}

ACEVEDO, C. R.; NOHARA, J. J. Monografia no curso de Administração: guia completo de conteúdo e forma. 2. ed. São Paulo: Atlas, 2006.

BOURDIEU, Pierre. O poder simbólico. Rio de Janeiro: Bertrand Brasil, 1998.

CAPPELLE, M. C. A.; MELO, M. C. O. L.; BRITO, M. J. Relações de poder segundo Bourdieu e Foucault: uma proposta de articulação teórica para a análise das organizações. Organizações Rurais \& Agroindustriais, Lavras, v. 7. N. 3, p. 356-369, 2005.

CHIZZOT'TI, A. Análise de conteúdo, análise de narrativa, análise do discurso. In: CHIZZOT'TI, A. (Org.). Pesquisa qualitativa em ciências humanas e sociais. 4. ed., Petrópolis, RJ: Vozes, 2006, p. 113134. 
DEMO, Pedro. Introdução à metodologia da ciência. 2 ed. São Paulo: Atlas, 1985.

FARIA, J. H. Poder e participação: a delinquência acadêmica na interpretação tragtenberguiana.

Revista de Administração de Empresas, São Paulo, v. 41, n. 3, p 70-76, jul./set. 2001.

FISCHER, R. M. O círculo do poder: as práticas invisíveis de sujeição nas organizações complexas. In: FLEURY, M. T. L.; FISCHER, R. M. (Coords.). Cultura e poder nas organizações. São Paulo: Atlas, 1989.

\section{FISCHER, T.; MAC-ALLISTER, M. Nota}

Técnica: jogando com cultura organizacional. In: CLEGG, S. R. et al. (org.). Handbook de estudos organizacionais: reflexões novas direções. V.2. São Paulo: Atlas, 2001. p. 252-259.

GIGLIO, E.; PUGLIESE, R. L.; SILVA, R. $\mathrm{M}$. Análise dos conceitos de poder nos artigos brasileiros sobre redes. Revista de Administração da Unimep, v. 10, n. 3, p. 51-69, 2012.

GRAY, D. E. Pesquisa no mundo real. 2. ed. Porto Alegre: Penso, 2012.

GUEDES, V. L. S.; BORSCHIVER, S. Bibliometria: uma ferramenta estatística para a gestão da informação e do conhecimento, em sistemas de informação, de comunicação e de avaliação científica e tecnológica. In: ENCONTRO NACIONAL DE CIÊNCIA DA INFORMAÇÃO, 6., 2005, Salvador. Anais... Salvador, 2005. p. 1-18.

HARDY, C.; CLEGG, S. R. Alguns ousam chama-lo de poder. In: CLEGG, S. R. et al. (org.). Handbook de estudos organizacionais: reflexões novas direções. V.2. São Paulo: Atlas, 2001. p. 260-292.

KICH, J. I. D. F.; PEREIRA, M. F.; SIMON, V. P.; COSTA, A. M. Relações de poder no processo de planejamento estratégico. R. Adm. FACES Journal, Belo Horizonte, v. 2, n. 2, p. 85-106, abr./jun. 2012.

LOCKE, L. F.; SILVERMAN, S. J.; SPIRDUSO, W. W. Reading and understanding research. 3. ed. SAGE Publications. 2010.

MACIAS-CHAPULA, C. A. O papel da informetria e da cienciometria e sua perspectiva nacional e internacional. Ciência da Informação, v. 27, n. 2, p. 134-140, mai./ago. 1998.
MIRANDA, S. O tabu do poder e da política nos estudos organizacionais. Revista de Administração da Universidade Federal de Santa Maria, v. 2, n. 1, p. 10-20, jan./abr. 2009.

MOZZATO, A. R.; GRZYBOVSKI, D. Análise de conteúdo como técnica de análise de dados qualitativos no campo da administração: potencial e desafios. Revista de Administração Contemporânea, v. 15, n. 4, p. 731-747, 2011.

OLIVEIRA, L. F. C; SACOMANO NETO, M.; BOAVENTURA, J. M. G. Influência do poder nas redes de negócio - análise da evolução da teoria. REAd, v. 83, n. 1, p. 01-25, 2016.

OTLET, P. O livro e a medida bibliometria. In: FONSECA, Edson Nery da. (Org.). Bibliometria: teoria e prática. 1. ed. São Paulo: Cultrix: Editora da Universidade de São Paulo, 1986. p. 19-34.

PAZ, M. G. T.; MARTINS, M. C. F.; NEIVA, E. R. O poder nas organizações. In: ZANELLI, J. C.; BORGES-ANDRADE, J. E.; BASTOS, A. V. B. (Org.). Psicologia, Organizações e Trabalho no Brasil. Porto Alegre: Artmed, 2004. p. 300-328.

RICHARDSON, R. J. et al.. Pesquisa social: métodos e técnicas. 3 ed. São Paulo: Atlas, 2015.

SAMPIERI, R. H.; COLLADO, C. F.; LUCIO, P. B. Metodologia de pesquisa. 5. ed. São Paulo: McGraw-Hill, 2013.

SANTOS, G. A. F.; CLARO, J. A. C. S. Poder e Política nas Organizações, à Luz das Teorias Organizacionais: Um Estudo Bibliométrico nos Anais do EnANPAD. Revista Eletrônica Gestão e Serviços, v. 5, n. 1, p. 812-826, 2014. 